\title{
Aspirações e Status Ocupacional: Qual a distância entre o sonho e a realização?
}

\author{
Marta Santos Sales'
}

Danielle Cireno Fernandes²

Resumo: Este trabalho é sobre status ocupacional e educação e busca sua relação com as aspirações ocupacionais apresentadas na adolescência. Para tanto, são consideradas a condição socioeconômica, o trabalho na adolescência e o gênero como fatores que influenciam esse processo. O estudo foi realizado com sujeitos da região metropolitana de Belo Horizonte, em duas etapas, ao longo de cinco anos (2009-2014), consistindo em um estudo longitudinal, que verificou o alcance das aspirações ocupacionais expressas na adolescência, cinco anos depois.

Palavras-chave: aspirações; expectativas; status; trabalho e gênero.

Aspirations and Occupational Status: How far is the dream from the realization?

Abstract: This work is about education and occupational status and search their relation to occupational aspirations presented in adolescence. For this purpose, they areconsidered socioeconomic status, work in adolescence and gender as factors that influence this process. The study was conducted with subjects from the

\footnotetext{
$1 \quad$ Universidade Federal de Minas Gerais (UFMG) - Belo horizonte - Brasil - martas@pbh.gov.br.

2 Departamento de Sociologia - Universidade Federal de Minas Gerais (UFMG) - Belo Horizonte - Brasil - daniellecf@gmail.com.
} 
metropolitan region of Belo Horizonte, in two stages, over five years (2009-2014), consisting of a longitudinal study, which verified the extent of occupational aspirations expressed in adolescence five years later.

Keywords: aspirations; expectations; status; work; and gender.

\section{Apresentação}

Este artigo apresenta parte dos resultados da tese de doutorado intitulada Aspirações Ocupacionais e Realização do Status, defendida em 2014, na Universidade Federal de Minas Gerais.

O objetivo dessa pesquisa foi estudar a importância das aspirações ocupacionais e expectativas dos outros significantes no início da trajetória ocupacional dos indivíduos, problematizando a desigualdade socioeconômica e de gênero e a prática de trabalho na adolescência. Buscamos explicar o grau de associação entre aspirações educacionais e ocupacionais na adolescência e o alcance do status educacional e ocupacional cinco anos depois.

$O$ estudo foi realizado com uma amostra intencional de jovens da região metropolitana de Belo Horizonte. Os dados são qualitativos e compuseram um estudo longitudinal que possibilitou o encontro com os sujeitos da pesquisa alguns anos (cinco) depois das primeiras entrevistas (2009) para verificar o status ocupacional e educacional na segunda etapa da coleta de dados, que foi realizada em 2014 ( $1^{\text {a }}$ etapa: 15 a 17 anos de idade; $2^{\text {a }}$ etapa: 20 a 22 anos de idade).

Consideramos adolescência uma construção social moderna, que envolve questões políticas, como a proteção da criança e do adolescente (BRASIL, 1990), e teóricas, pois... "as práticas sociais podem chegar a engendrar domínios de saber que não somente fazem aparecer novos objetos, novos conceitos, novas técnicas, mas também fazem surgir formas totalmente novas de sujeitos..." (Foucault, 1996: 8).

A forma como os diferentes grupos populacionais se inserem no mercado de trabalho retrata uma face importante da desigualdade. Homens e mulheres, bem como indivíduos oriundos de diferentes estratos socioeconômicos apresentam características bem distintas no processo de constituição das aspirações ocupacionais, na influência que recebem dos pais, na entrada no mercado de trabalho, nos postos ocupados, nos rendimentos auferidos e nas áreas de atuação. A partir dessa discussão, algumas questões foram levantadas: O nível de aspirações ocupacionais varia de acordo com as expectativas sociais sobre elas, considerando gênero, condição socioeconômica e o 
trabalho na adolescência? O grau de associação entre as aspirações educacionais e ocupacionais na adolescência e o alcance do status educacional e ocupacional na vida adulta é mediado pelo gênero, condição socioeconômica e trabalho na adolescência?

\section{Literatura}

No início do Século XX, na interface Sociologia/ Psicologia, George Mead e Charles Cooley criaram as teorias que representaram a base para o surgimento do interacionismo simbólico (Featherman; Haller, 2007).

Após a morte de Mead, em 1931, é Blumer quem dá continuidade aos cursos proferidos por ele, sendo o interacionismo simbólico uma corrente iniciada em Chicago por Blumer (Farr, 1996).

Mead propôs uma filosofia completa da ação e Blumer estava interessado na interpretação da ação; o primeiro era filósofo e abordou muitos dos problemas da filosofia da época, enquanto Blumer era sociólogo de formação. $\mathrm{O}$ grande interesse de Blumer estava na metodologia das ciências sociais e no comportamento coletivo. Ele selecionou da obra de Mead, principalmente, o que se referia à forma pela qual a cultura e as normas são internalizadas pelas pessoas (Farr, 1996).

Honneth reelabora a teoria do reconhecimento intersubjetivo de Hegel, aproximando-se do entendimento de Mead sobre a constituição do self. Para Salvadori (2003), Honneth trata da inserção dos indivíduos e grupos na sociedade por meio da luta por reconhecimento intersubjetivo, que se inicia pela experiência do desrespeito das formas de reconhecimento. "A auto-realização do indivíduo somente é alcançada quando há, na experiência de amor, a possibilidade de autoconfiança, na experiência de direito, o auto-respeito e, na experiência de solidariedade, a auto-estima." (Salvadori, 2003: 189).

Essa discussão faz parte da fundamentação desse trabalho, buscando explicar a relação entre aspirações ocupacionais e expectativas dos outros significantes por meio da aplicação empírica das teorias de Mead. Destaca-se também o modo como a teoria de Mead evolui do reconhecimento subjetivo recíproco entre indivíduos para a aquisição das normas sociais. Assim, a imagem própria que o indivíduo aprende a conceber-se da perspectiva do outro generalizado ou do social é entendida como a compreensão de uma pessoa de direito (Honneth, 2009).

Os estudos mais importantes que experimentaram empiricamente a teoria do self social de Mead foram os de Wisconsin, consistindo em uma coleta de 
dados, em 1957, com uma amostra composta por jovens de origem rural que estavam no ensino médio, e outra em 1964, quando $89 \%$ da amostra foi entrevistada novamente para verificar a realização ocupacional e educacional, acrescentando à amostra indivíduos com origem de diferentes comunidades (urbanas e rurais) e com diferentes níveis socioeconômicos. Essas pesquisas investigaram estatisticamente (regressão linear) a influência de variáveis subjetivas como o outro significante e habilidades mentais no alcance educacional e ocupacional (Sewell; Haller; Ohlendorf, 1970).

Concomitante a esse trabalho, Blau e Ducan contribuíram para a área de estratificação social, analisando o efeito de características da família, como nível educacional e ocupacional dos pais no status ocupacional do primeiro emprego do indivíduo e na vida adulta (Blau; Ducan, 1967).

Blau e Ducan adotam uma perspectiva individualista-voluntarista, tendo como foco os fatores na história do indivíduo que explicam seu nível de realização socioeconômica, de modo que possa descrever as carreiras das pessoas. Esse estudo de Blau e Ducan representou o retorno da pesquisa sociológica aos estudos da psicossociologia, por volta de 1950, quando introduziram a expressão Life Course Sociology para explicar o processo de estratificação (Featherman; Haller, 2007).

Com relação aos coeficientes encontrados no modelo de 1964, os coeficientes da performance acadêmica foram maiores no nível de aspiração ocupacional. A implicação disso é que o maior nível de desempenho acadêmico tem efeito direto nas expectativas dos outros significantes, no nível educacional, nas aspirações ocupacionais (Sewell; Haller; Ohlendorf, 1970).

\section{Método}

Os dados foram extraídos de 77 entrevistas, sendo 40 realizadas entre julho e setembro de 2009 e as demais entre dezembro de 2013 e janeiro de 2014, representando um estudo longitudinal. Em 2009, foram selecionados intencionalmente 20 adolescentes da região metropolitana de Belo Horizonte, com idade entre 15 e 18 anos, que estavam cursando o ensino médio, mais os respectivos pais.

Buscamos compor dois grupos de condição socioeconômica (condição socioeconômica desfavorecida - CSD - e condição socioeconômica média - CSM). No interior de cada um dos grupos, metade dos adolescentes trabalhava e a outra metade não. E metade foi composta por homens e a outra metade por mulheres, como está indicado no quadro abaixo. 


\begin{tabular}{|c|c|c|}
\hline \multicolumn{3}{|c|}{ Quadro 1. Grupos da amostra (2009-2013/14) } \\
\hline & Trabalhavam & Não trabalhavam \\
\hline $\mathrm{CSD}^{*}$ & $\begin{array}{l}3 \text { mulheres } \\
2 \text { homens }\end{array}$ & $\begin{array}{l}2 \text { mulheres } \\
3 \text { homens }\end{array}$ \\
\hline $\mathrm{CM}^{* *}$ & $\begin{array}{l}2 \text { mulheres } \\
3 \text { Homens }\end{array}$ & $\begin{array}{l}3 \text { mulheres } \\
2 \text { homens }\end{array}$ \\
\hline
\end{tabular}

${ }^{*}$ CSD: Condição socioeconômica desfavorecida

** CSM: Condição socioeconômica média

Para atender aos critérios de condição socioeconômica e trabalho na adolescência com a garantia de que os perfis necessários seriam encontrados, algumas estratégias de investigação foram sendo adotadas no decorrer da formação da amostra. As cinco instituições nas quais os sujeitos foram encontrados foram escolhidas na seguinte sequência temporal: de antemão, contava-se com o contato de uma fundação e uma associação (Programa Educação \& Trabalho da Fundação CDL e Associação Profissionalizante do Menor - ASSPROM) que encaminham e acompanham adolescentes, em condição de vulnerabilidade social, que trabalham como aprendizes e estavam estudando. Para que outro grupo na mesma condição socioeconômica fosse preenchido com sujeitos que não trabalhassem, buscou-se uma escola estadual próxima à uma região vulnerável (Pedreira Prado Lopes - Bairro Lagoinha), na qual os alunos não trabalham, porque é uma escola diurna (Colégio Estadual Silviano Brandão). Nessa escola, com auxílio da secretaria e coordenação do colégio, teve-se a preocupação de procurar aqueles jovens que recebiam complemento de renda do governo federal ou estadual (Bolsa Escola/ Bolsa Família), considerando que passaram por uma avaliação baseada no critério de renda.

Além disso, grande parte da coleta foi realizada nas residências das famílias (entrevistas dos pais), de modo que foi possível observar que todas as famílias desse grupo viviam em zonas de risco, exceto uma que vivia nas proximidades, em um apartamento alugado e bem pequeno. As ocupações dos pais formam um perfil diferente daqueles pais do estrato de classe média. Outro ponto semelhante a todo esse grupo (que não esteve presente no grupo em CSM) foi a ausência de automóvel no domicílio em todas essas famílias em CSD. Para compor o grupo em CSM, inicialmente, buscou-se uma escola técnica federal (Centro Federal de Educação Tecnológica de Minas Gerais - CEFET-MG/classe 
média) na qual é muito comum que os alunos trabalhem por ser uma escola técnica na qual o horário não é integral. Quando a pesquisadora estava na escola, em contato com a coordenação, buscou informação a respeito da condição econômica dos alunos daquela escola. As informações eram de que nessa escola não havia alunos em vulnerabilidade social, que morassem em área de risco, por exemplo. Outro ponto importante foi observar que para entrarem na escola todos passam por uma seleção com certo grau de exigência, de modo que é necessário fazer um curso preparatório na maior parte dos casos e ter um bom histórico escolar. Esses dados deram segurança de que os alunos dessa escola pertenciam a CSM, no mínimo.

Por último, procurou-se uma escola particular (CSM) onde há adolescentes que geralmente não trabalham (Colégio Berlar São Pascoal). No entanto, como as entrevistas do CEFET já tinham sido realizadas e já tinha sido observado que o grupo composto pertencia a uma CSM, notou-se que era importante que fosse uma escola particular com uma mensalidade não muito alta. A mensalidade na época girava em torno de $\mathrm{R} \$ 400,00$ (quatrocentos reais). Foram escolhidos alunos que recebiam $50 \%$ de bolsa.

Portanto, o mais importante na seleção da amostra foi equiparar a condição socioeconômica, ficando, por um lado, os programas de trabalho e a escola estadual (condição socioeconômica desfavorecida); e, por outro, a escola particular e a escola técnica (condição socioeconômica média).

Os procedimentos adotados para coleta de dados realizada em 2009 e em 2014 consistiram em entrevistas em profundidade com os jovens e os respectivos pais, separadamente.

Todas as falas literais dos sujeitos da pesquisa que foram citadas a seguir são oriundas da segunda etapa de coleta de dados, realizada em 2014.

\section{A relacão entre aspirações ocupacionais e alcance educacional e ocupacional: desigualdade socioeconômica}

Comparamos aspirações ocupacionais e expectativas (jovens e respectivos pais) relatadas pelos sujeitos entrevistados em 2009 com aspirações, expectativas e vivências laborais e educacionais que os mesmos viviam em 2014, considerando condição socioeconômica (estrato médio - CSM - e desfavorecido - CSD), sexo (homem e mulher) e trabalho na adolescência.

Observamos um padrão extremamente diferenciado entre aqueles oriundos do estrato socioeconômico desfavorecido que trabalhavam em 2009 e todos que pertenciam ao estrato médio, pois os primeiros apresentaram (2014) 
aspirações bastante diferentes das indicadas por eles anteriormente (2009), decrescendo suas aspirações em nível de status e rendimento. Eles mantiveram expectativas de rendimentos, mas reduziram o status da ocupação (de médica para secretária, de enfermeira chefe para cabeleireira e de engenheiro para supervisor de telemarketing) ou mantiveram o nível de status (empresário), mas reduziram o rendimento (de 6 mil reais para 2 mil) e outros continuavam sem aspirações definidas. Enquanto os jovens desse estrato que não trabalhavam mantiveram o nível de status das aspirações almejadas, pois já eram um pouco mais baixas em 2009.

Esses dados demonstraram que o efeito positivo do trabalho que se evidenciou em $2009^{3}$ foi reduzido com o passar de cinco anos, uma vez que o efeito negativo da condição socioeconômica sobressaiu como fator determinante na trajetória dos indivíduos estudados, como veremos ao longo do texto.

Por outro lado, ao considerar o estrato CSM, os níveis de status ocupacional (empresário(a), engenheiro(a) mecânico(a), engenheiro elétrico, empresa de relações públicas) se mantiveram altos ou aumentaram ainda mais; e com relação ao rendimento esperado para a ocupação correspondente, somente aumentaram, sendo o mais baixo 3 mil reais em 2009 e a média da coorte 2014 esteve em torno de 9 mil reais e as expectativas mais altas chegaram a 20 mil reais.

A disparidade entre as aspirações dos dois estratos retrata a desigualdade socioeconômica e injustiças inerentes a tal realidade, uma vez que aqueles oriundos de estratos socioeconômicos menos favorecidos aspiram, gradativamente (da adolescência para a vida adulta), ocupações e rendimentos menos valorizados. Embora possamos interpretar esses dados dizendo que os sujeitos esperam o que podem conquistar diante da realidade material em que se encontram, e, portanto, podemos pensar que não aspiram mais porque não conhecem outras profissões (Khattab, 2003), pode-se dizer ainda que a estrutura social reproduz a desigualdade social até nos aspectos mais subjetivos, como as aspirações ocupacionais. Essas são determinantes para a realização ocupacional efetiva do indivíduo (Lapan; Hinkelman; Adans; Turner, 1999), pois não apenas se produzem em um contexto social, como também constituem a motivação e engajamento necessários para o desenvolvimento da trajetória profissional.

3 Em 2009, as aspirações mais altas foram daqueles do estrato médio que trabalhavam, seguidos juntamente pelos do mesmo estrato que não trabalhavam e os do estrato desfavorecido economicamente que trabalhavam; por último, apareceram os que não trabalhavam do estrato desfavorecido. Assim, foram três níveis: CSM e trabalho $\rightarrow$ CSM e não trabalho + CSD e trabalho $\rightarrow$ CSD e não trabalho. Para identificar o nível de aspirações, consideraram-se cargos indicados e o nível de conhecimento com relação à área, bem como entusiasmo e engajamento no projeto pessoal. 
A literatura sobre aspirações, desde as pesquisas de Wiscosin (Seweell; Haller; Orlendorf, 1970), apresenta que condição socioeconômica está diretamente correlacionada com aspirações e expectativas. No entanto, um caso anômolo apresentado por Khattab (2003) esclarece os mecanismos subjacentes da condição socioeconômica como determinante das aspirações e realizações subsequentes. Em Israel, palestinos apresentam alto nível de aspirações educacionais a despeito das dificuldades que vivem. Dentre os palestinos e judeus de Israel, os primeiros apresentam uma condição socioeconômica bem inferior à dos judeus e a proporção de palestinos no ensino superior é maior do que a de judeus. $\mathrm{O}$ autor explica que a segregação educacional dos palestinos possibilita que eles se valorizem entre si e não permite que sejam expostos a comparações com relação aos demais, de modo que suas fraquezas fiquem expostas. Assim, acabam desenvolvendo alto nível de aspirações.

Kao e Tienda, ${ }^{4}$ citados por Khattab (2003), demonstram que o mesmo ocorre com estudantes negros americanos, que se mantêm segregados no ensino. Pode-se dizer que a forma como os estudantes minoritários percebem sua realidade social e econômica e suas chances no sistema educacional e no mercado de trabalho são cruciais para determinar se eles desenvolverão altas ou baixas aspirações (Khattab, 2003).

A partir disso, estudantes minoritários não se esforçam para atingir um objetivo particular por não acreditarem que os resultados seguem como consequência direta do sucesso de suas performances nas tarefas escolares (Lapan; Hinkelman; Adams; Turner, 1999), de modo que a percepção que os estudantes têm de suas chances futuras influenciam seus comportamentos e suas crenças, fazendo com que acreditem em possibilidades reais no mercado de trabalho e se dediquem a terem um melhor desempenho escolar.

A partir disso, associamos as aspirações (2009 e 2014) com as motivações para o estudo e trabalho relatadas em 2014, evidenciando o baixo envolvimento dos jovens oriundos do estrato socioeconômico desfavorecido com o estudo e apresentaram como principal finalidade do trabalho suprir necessidades materiais imediatas.

Um dado que chamou bastante atenção durante as entrevistas foi a evidência de que apenas no estrato socioeconômico desfavorecido havia jovens que não concluíram o ensino médio e evadiram da escola (50\%), ao passo que $100 \%$ dos que possuíam CSM concluíram o ensino médio. Além disso, todos desse

4 Kao, G.; Tienda, M. (1998). Educational aspirations of minority youth. American Journal of Education, $106,349-384$. 
estrato estavam estudando em 2014, enquanto apenas dois dentre os dez oriundos do estrato CSD estavam estudando. Esse dado é alarmante, considerando que cinco anos antes todos estavam na série regular e todos pretendiam concluir o ensino médio. Embora ao serem questionados com relação à motivação que encontram para estudar, os dois grupos se assemelharam com relação aos motivos declarados. ${ }^{5}$ Nos trechos a seguir, as falas dos jovens indicam o nível de envolvimento com o estudo pela extensão de suas falas e pelos reais motivos relacionados (conhecimento, financeiro). Além disso, situações da realidade social deles movem seus interesses para a preocupação em cuidar de terceiros (pais e filhos) e dar-lhes uma vida melhor, o que ocorre apenas no grupo com condição socioeconômica desfavorecida:

CSD: Interesse de ganhar mais e porque eu gosto da área, aprendi a gostar, porque é uma forma de está mais perto do Marcos (nome fictício - filho), posso levar e buscar o Marcos na escola. Eu escolhi essa área por isso (Trabalhava na adolescência/ mulher).

Ser alguém na vida (risadas). Ficar dependendo dos outros não dá por muito tempo. Dar uma vida melhor aos meus pais também, sempre é bom (Não trabalhava na adolescência/ homem). Infelizmente nada, um futuro melhor financeiro, estabilidade (...) (Não trabalhava na adolescência/ Mulher).

No entanto, um jovem desse estrato se destacou como um caso anômalo ao apresentar diversas respostas extremamente diferentes do seu estrato e raras no estrato médio também: “(...) porque proporciona um futuro melhor, mais aprendizado, para ser uma pessoa mais culta. Escolhi Letras porque é o que eu gosto de fazer, gosto muito de literatura (...) (Trabalhava na adolescência/ Homem)".

Esse jovem precisava conseguir um trabalho como vendedor no shopping, então ele tentou em uma livraria, pois assim conseguia comprar os livros com desconto e ficava no ambiente que gostava. Anteriormente, teve outros trabalhos. Ele apresentava alto nível de aspirações, pelo envolvimento com a leitura e com sua área de interesse e pelas motivações apresentadas para o estudo e trabalho, embora sua condição socioeconômica imponha grandes desafios à sua trajetória, uma vez que iniciou dois cursos superiores e teve que interromper o primeiro (engenharia química) porque não gostou e o segundo (Letras), porque

5 Todos relataram querer estudar para: ganhar mais, conhecimento, independência, crescimento profissional, conhecimento para fazerem o que gostam e porque é a área que o pai também gosta. 
teve dificuldades financeiras, conforme ele relatou: "Eu estava fazendo cursinho pré-vestibular pra tentar passar na UFMG, porque eu parei de fazer a faculdade, porque era uma faculdade particular e estava ficando muito caro (...)" (Idem).

O jovem reside com sua mãe e irmão na casa de sua avó e a sua mãe ganha um salário mínimo como auxiliar administrativa e vendedora em uma loja, enquanto seu pai é motorista. Os pais não puderam ajudá-lo a pagar a faculdade, de modo que ele precisou interromper o curso superior que iniciou, o que o impede de ter um trabalho na área que gosta, como um estágio, por exemplo, como é o caso de todos os jovens do estrato CSM da amostra.

Por outro lado, os sujeitos da pesquisa que pertenciam ao estrato CSM demonstraram maior interesse no conhecimento e não apresentavam preocupação econômica e necessidade de retorno imediato, indicando um quadro de estabilidade:

O crescimento profissional né. Curso superior é muito importante para sua vida, conhecimento nunca é demais. Eu pretendo fazer mestrado, doutorado, seguir nessa linha assim. Escolhi esse curso porque eu já estudei engenharia de edificações no técnico e o grau de dificuldade me intriga sabe? Acho que isso me motiva. A questão da matemática, que eu gosto muito, a remuneração (Trabalhava na adolescência/ Homem).

A vontade de ter um futuro bom, uma carreira boa e também atuar numa área que eu goste, não ficar nessas profissões que a gente não estuda tanto, mas não é tão legal quanto a que eu quero fazer (Trabalhava na adolescência/ Mulher).

Acho que é a busca por um salário melhor, uma vida financeira melhor (Trabalhava na adolescência/ Mulher).

Eu sempre gostei de mexer com criação, essas coisas. Aí, surgiu a ideia de fazer esse curso, pra unir o útil ao agradável (Não trabalhava na adolescência/ Homem).

Eu escolhi por mim e por meu pai, que tem colegas que trabalham nessa área e disseram que o curso é bom e que essa área só tende a crescer. Além disso, as matérias que eu mais gosto são exatas (Não trabalhava na adolescência/ Homem).

Olha, primeiramente, questão de gosto, porque eu gosto muito de trabalhar nessa área e eu vejo que eu me desenvolvo melhor, minha desenvoltura 
para lidar com pessoas no canteiro de obra, porque é preciso saber lidar com pessoas diferentes em todas as situações. Essa é a minha maior motivação. E em toda a vida, espelhando-me em meu pai eu acabei gostando, porque ele sempre gostou (Não trabalhava na adolescência/ Homem).

Eu acho que escolhi o curso certo e quando a gente faz o que a gente gosta, não tem nada que pare a gente. Na época que você me entrevistou eu sempre fui apaixonada por Psicologia e nas Relações Públicas eu descobri uma forma inteligente de usar a Psicologia que é para o lado organizacional/ social, com um motivo maior, que é o relacionamento (Não trabalhava na adolescência/ Mulher).

A comparação entre as motivações apresentadas para o trabalho demonstrou desigualdade da mesma forma que as aspirações. Os jovens do estrato CSD apontaram como motivações para o trabalho a necessidade de dinheiro para cobrir as necessidades pessoais e, para os demais, a motivação para o trabalho era fazer o que gosta e praticar o que estuda, embora alguns contribuam no pagamento da faculdade.

Portanto, para os casos estudados, observamos que o nível de aspirações ocupacionais se apresenta de forma estratificada por meio das perspectivas que os jovens relatam, de modo que aqueles oriundos do estrato favorecido socioeconomicamente aspiram mais porque percebem mais possibilidades reais e possuem melhores condições materiais para conquistar o que desejam (Khattab, 2003; Lapan; Hinkelman; Adams; Turner, 1999).

A compreesão a respeito das aspirações ocupacionais e dos processos envolvidos se dá a partir da relação entre indivíduo e outro significante, pois todos os aspectos subjetivos, como aspirações, resultam da interação social, formando o self refletido, de modo que o eu ou a identidade seja social. Para Mead, os outros significantes são as pessoas que exercem maior influência sobre as atitudes do indivíduo por meio de uma relação emocional intensa. Na infância, geralmente são os pais ou quem cria a criança. Nas fases posteriores, os indivíduos costumam selecionar inconscientemente outros atores que também exercerão esse papel. $\mathrm{O}$ outro significante transmite o que pensa a respeito do indivíduo, por meio da fala, de gestos, forma de olhar e atitudes durante a interação diária. Cada um interpreta tais mensagens atribuindo significados a elas de acordo com as experiências anteriores ( self-reflection), formando sua autoimagem (Mead, 1934). "Os pais estabelecem com os filhos uma comunicação intersubjetiva através da linguagem, de modo que os sujeitos captam as mensagens do 
outro e as simboliza, acabando assim por assumir as atitudes e papel do outro" (Mead, 1934: 160-161, tradução nossa).

Assim, as expectativas dos pais (outro significante) com relação aos filhos explicam as aspirações ocupacionais porque fazem parte do processo de constituição dessas. Então, analisamos as expectativas dos outros significantes com relação aos sujeitos estudados, considerando-as parte ativa do processo.

Nesse estudo, as pessoas indicadas como outro significante foram os pais somados a outras pessoas, representadas por irmãos, namorado(a) e avó, geralmente. Apenas uma jovem não mencionou os pais entre as pessoas que exercem maior influência em suas vidas, indicando a avó e o companheiro. Não se observou diferenças significativas nas pessoas indicadas como outro significante, considerando condição socioeconômica ou gênero.

As expectativas ocupacionais dos pais com relação aos seus filhos indicaram o mesmo padrão das aspirações ocupacionais dos sujeitos, pois apenas no estrato CSD houve alterações significativas nas expectativas entre o ano de 2009 e 2014. Entretanto, alguns outros significantes desse estrato reduziram o nível de expectativas com relação aos filhos e, nesses casos, os filhos haviam apresentado um desempenho inferior ao esperado, não concluindo o ensino médio e/ ou apresentando comportamentos totalmente desaprovados pela família, como usar drogas e não estudar ou trabalhar. Em um caso, a mãe mudou suas expectativas, de acordo com as mudanças nas aspirações da filha (de enfermeira chefe para cabeleireira) e, nesse caso, embora o nível de status ocupacional das aspirações tenha reduzido também, o rendimento se manteve.

Considerando ainda o estrato CSD, as expectativas dos outros significantes foram mais elevadas com relação aos homens, pois apenas com relação a algumas mulheres eles apresentaram expectativas negativas quando as filhas não haviam concluído o ensino médio. Por outro lado, os pais dos meninos que não concluíram o ensino médio não demonstraram descrença no potencial do filho por meio da linguagem; ou ainda o filho parou de estudar, mas os outros signifcantes mantiveram o mesmo nível de expectativas. A partir das expectativas apresentadas em 2009, há apenas uma difrença sutil entre homens e mulheres, que se apresentava como destacamos a seguir:

2009: Quero que ela tenha o segundo grau para ela poder escolher. Eu acho que essas pessoas que dão aula de computação é um bom emprego.

2013/14: Eu acho que ela não gosta de estudar, não esforça. Era pra ter formado no segundo grau, por preguiça não terminou. Se ela continuar 
desse jeito, ela vai continuar sendo caixa (Mãe da jovem que trabalhava na adolescência/ mulher).

2009: Ela diz que vai ser advogada. Eu acho que tem a possibilidade de ela ser o que ela quer.

2013/14: se ela não tomar consciência de que o que ela está fazendo está errado, ela vai está igual muita gente que eu vejo por aí, na rua, sem casa, sem teto, usuário de drogas, porque sinceramente ela vai pela cabeça dos outros. Ele teve oportunidade de trabalhar aqui pela Claro, mas ela não quis (Mãe da jovem que não trabalhava na adolescência/ mulher).

2009: Eu escolheria um engenheiro porque desde pequeno ele faz uns desenhos e diz isso. Ele terá uma empresa ou será sócio. 2013/14: Engenheiro civil que ele falava (Mãe de jovem que trabalhava na adolescência/ homem).

A partir dos trechos acima, observa-se entre os dois primeiros (referem-se à filha mulher) e o terceiro (refere-se a um filho homem) uma diferença de tratamento, sendo que todos os três pararam de estudar, de modo que as mães das mulheres utilizaram palavras pejorativas e têm uma expectativa negativa com relação às filhas, enquanto a mãe do homem, embora ele tenha parado de estudar também, manteve a mesma expectativa ocupacional com relação ao filho. A mãe de outro jovem que parou de estudar e, além disso, teve problemas com a justiça (ficou preso devido a envolvimento no tráfico de drogas) não apresentou uma fala desrespeitosa ou descrente com relação ao filho: "A gente pensa sempre estar melhor. Ele pode estar trabalhando em outra coisa diferente. Eu não sei, claro que ele vai ter uma cabeça mais madura e ele vai ver o que é melhor pra ele." Os pais se comportam diferentemente com homens e mulheres, refletindo certa desigualdade social entre os sexos. Isso se deu porque os OS notam o maior prejuízo que as filhas terão ao não se dedicarem aos estudos, uma vez que dependem mais da educação do que os homens (Aguiar; Fernandes; Neves, 2007) ou porque destinam menos valor às mulheres. De todo modo, o preconceito de gênero se evidencia nessas relações.

Ao observar as expectativas que os sujeitos percebem e compará-las com as expectativas que foram realmente declaradas pelos pais, é possível compreender a relação entre aspirações e expectativas, pois, conforme Cooley (1922), os sentimentos acerca de quem somos dependem, em grande medida, de como nós nos vemos avaliados pelos outros. Assim, como vemos nosso corpo refletido em um 
espelho, do mesmo modo vemos nosso "eu" social refletido nas gesticulações e reações que os outros nos dirigem.

De modo geral, as percepções dos jovens entrevistados com relação às expectativas dos outros significantes indicaram bastante semelhança ao que os pais relataram ter como expectativas sob eles. Considerando a condição socioeconômica, no estrato médio, todos notam expectativas positivas por parte dos outros significantes, enquanto no estrato CSD, alguns (um homem e uma mulher) percebem expectativas negativas por parte de um dos pais. Considerando o gênero, evidenciou-se certa desigualdade no interior do estrato CSM, pois os homens apresentaram aspirações mais altas do que as mulheres, e perceberam as expectativas reais dos outros significantes, enquanto que as jovens relataram as expectativas dos pais abaixo do que eles demonstravam.. Desse modo, evidenciou-se haver algo no processo de comunicação entre pais e filhos que é interpretado pelas jovens de forma distorcida, apontando que o outro existe na imaginação do indivíduo e atua sobre ele por meio da sua simbolização. A comunicação é a fonte imediata do self, pois é na imaginação que ambos, o self e o outro, têm origem (Mead, 1930).

Para Blumer (1986), na interação, as pessoas assumem os papéis uns dos outros para compreenderem o que eles pensam uns sobre os outros. Quem responde a uma situação, busca captar o que o outro pensa sobre ele ao se colocar em seu lugar. Vale ressaltar que esse processo é orientado subjetivamente, em uma comunicação consigo mesmo, de modo que o próprio ator social interpreta e significa a situação.

Assim, as aspirações se constituem na relação com as expectativas, mediadas por vários fatores, como a desigualdade socioeconômica e a de gênero, aspectos da realidade social estudada que impõem sérios limites aos sonhos dos jovens, uma vez que o contexto que o indivíduo cresce o forma, influenciando suas associações, sua conduta, suas características, sua personalidade e sua organização mental, que é formada a partir das associações que são seguidas (Blumer, 1937).

Por fim, associamos as aspirações relatadas em 2009 com as realizações efetivas em 2014, possibilitando verificar o efeito das aspirações ocupacionais realmente, de modo que nessa análise se consolida o maior objetivo do estudo longitudinal por meio da comparação entre o antes e o depois na vida dos sujeitos estudados.

Vimos que a condição socioeconômica foi determinante para concretizar as aspirações dos indivíduos estudados, pois todos (10 indivíduos) que pertenciam ao estrato médio atingiram seu objetivo de entrar na faculdade, conforme havia relatado que desejavam, cinco anos antes (2009). Por outro lado, apenas $20 \%$ entre os 
dez sujeitos estudados que pertenciam ao estrato desfavorecido economicamente iniciaram o curso superior, mas interromperam por dificuldades financeiras em manter o curso. Em 2009, 80\% dentre eles afirmaram aspirar fazer faculdade ao serem questionados quanto ao que pretendiam fazer cinco anos depois.

Com relação à associação entre aspirações ocupacionais em 2009 e o nível do status ocupacional em 2014, a desigualdade também aumenta, como ocorreu entre aspirações educacionais e nível educacional. As aspirações ocupacionais em 2009 eram sutilmente estratificadas, pois os cargos desejados não diferiam muito entre os estratos ou entre meninos e meninas, porém, o nível de entusiasmo, conhecimento sobre a área desejada (por exemplo, o rendimento esperado) e engajamento em um projeto pessoal indicavam diferenças. Já o nível ocupacional atingido em 2014 desvelou a forte desigualdade entre os estratos, uma vez que os cargos ocupados e rendimentos auferidos diferem muito entre os jovens dos dois estratos, enquanto diferenças entre homens e mulheres não ficaram evidentes a partir dos dados de 2014.

\section{Conclusão}

Esses dados poderiam ser explicados considerando a descrença dos sujeitos do estrato CSD nas realizações futuras, uma vez que convivem com pessoas que não atingiram realizações educacionais e ocupacionais mais altas (Khattab, 2003). No entanto, em 2009, eles aspiravam ocupações com nível de status mais elevado (engenheiro, enfermeira etc.) e, portanto, acreditavam que conseguiriam; isso pode significar que tal mudança decorra da realidade material desses jovens ao influenciar sua trajetória educacional. $\mathrm{O}$ contexto social atua na realização dos sujeitos por meio da menor dedicação dos pais à educação dos filhos, por exemplo. Conforme Bryant, Zvonkovic e Reynolds (2006), a classe social e o nível de stress resultante do trabalho dos pais determinam o tempo que podem disponibilizar para a educação dos filhos e qualidade dos momentos de convívio, uma vez que os pais são os principais responsáveis pelo processo de desenvolvimento vocacional dos filhos, mais do que a escola e amigos.

Com relação ao gênero, o que demosntrou um nível mais baixo de aspirações em 2009 (menos entusiasmo e autoconfiança) ou um perfil mais "pé no chão" pode ser interpretado agora como uma característica feminina (menos "empolgação"), que não apresentou efeito negativo em sua trajetória ocupacional, cinco anos depois. Essas evidências corroboraram com Ashby e Schoon (2010), que afirmam que as mulheres aprendem desde cedo que, se quiserem ser bem-sucedidas, não é suficiente apenas "sonhar alto", elas precisam se dedicar para isso. 
As aspirações e expectativas apresentam uma associação direta no caso do estrato CSM e no caso dos homens do estrato CSD, mas, a partir das mulheres do estrato CSD, ficou evidente que os pais alteram suas expectativas de acordo com o desempenho dos filhos mais do que o inverso, pois apenas no caso das mulheres oriundas desse estrato houve modificação de expectativas dos outros significantes quando as filhas apresentaram um desempenho bem inferior ao esperado. Isso evidencia que as mulheres sofrem uma cobrança mais rigorosa ou talvez sejam mais punidas pelos seus erros. Mas também indica que não há uma ordem causal no sentido de expectativas - aspirações - ou mesmo o contrário, pois o desempenho escolar contribui para as expectativas dos pais, de modo que há uma sincronia entre pais e filhos. Isso corrobora com Seweell, Haller e Orlendorf (1970), que notaram haver influência do outro significante (OS), mas adiciona que o desempenho acadêmico atua sobre os outros significantes e tem efeito nas aspirações e realizações que não são mediadas por eles (OS), o que significa que o indivíduo não é totalmente dependente do OS para orientar suas decisões sobre sua carreira e seu status (Seweell; Haller; Orlendorf, 1970).

Assim, a desigualdade socioeconômica propicia a não realização dos direitos para os indivíduos, que é um desrespeito a uma das formas de reconhecimento intersubjetivo para Honneth (2009), pois o direito de escolhas efetivas nos planos educacional e ocupacional não se concretiza devido aos impedimentos socioeconômicos.

Os mecanismos da desigualdade social atuam por meio dos pais ao apresentarem um olhar estratificado com relação aos filhos, de modo que transmitem valores sociais no processo de reconhecimento subjetivo recíproco entre indivíduos. Assim, a aquisição das normas sociais por meio do "olhar" dos pais indica a formação do outro generalizado, que é a percepção do que é correto para a sociedade e a ideia de ser socialmente aceito pela coletividade (Mead, 1934). Quando o reconhecimento não ocorre, o direito não se realiza, há desrespeito dos direitos sociais, dificultando a integração social, pois a cada conquista de comunitarização, os sujeitos entram num conflito intersubjetivo, resultando no reconhecimento de sua autonomia, o que representaria um desenvolvimento bem-sucedido do Eu, enquanto o desenvolvimento mal sucedido se dá pela experiência do desrespeito, levando os sujeitos a uma luta por reconhecimento (Honneth, 2009).

A partir disso, podemos observar que os sujeitos pertencentes ao estrato CSD estão passando pelas fases do seu desenvolvimento perdendo autonomia, uma vez que suas possibilidades de escolhas reduzem enquanto apreendem mais sobre o mundo, quando deveria ocorrer o inverso, o que é um desrespeito aos seus direitos e, portanto, a desigualdade socioeconômica provoca os 
desenvolvimentos educacional e ocupacional malsucedidos dos indivíduos por não terem acesso aos seus direitos sociais.

A associação entre aspirações e expectativas e o nível educacional e ocupacional dos sujeitos cinco anos depois estão fortemente associados, entretanto, quando mediamos tal associação com a estratificação social, observamos que os indivíduos oriundos do estrato desfavorecido economicamente alcançaram bem menos as aspirações anteriores, reduzindo o nível ocupacional e educacional ao contrário daqueles que pertenciam ao estrato médio, que obtiveram maior sucesso em seus objetivos. Por outro lado, o gênero e a prática de trabalho na adolescência não pareceram ser importantes no que se refere a atingir as aspirações, uma vez que meninas e meninos do mesmo estrato apresentaram o mesmo padrão de alcance de suas aspirações. Além disso, o trabalho, ao contrário do que se observou a partir dos dados de 2009, não demonstrou apresentar um efeito diferente no alcance educacional ou ocupacional em 2014, o que pode estar relacionado ao fato de o aprendizado do trabalho, que representava um diferencial em 2009, uma vez que elevava as aspirações, ter sido adquirido pelos demais (que não trabalhavam em 2009) quando começaram a trabalhar.

Assim, os resultados apontam que as aspirações ocupacionais, educação e status ocupacional revelam injustiças sociais por meio da restrição de escolhas efetivas no campo educacional e ocupacional para indivíduos oriundos de estratos socioeconômicos desfavorecidos.

\section{Referências}

AGUIAR, Neuma; FERNANDES, Danielle; NEVES, Jorge. A Mobilidade Social Feminina. In: AGUIAR, N. (Org.). Desigualdades Sociais, Redes de Sociabilidade e Participação Política. Belo Horizonte: Editora UFMG, 2007.

ASHHBY, Julie; Schoon, Ingrid. The role of aspirations, ambition and gender in predicting adult social status and earnings. Journal of Vocational Behavior. v. 77:3, 2010, p. 350 - 360.

BLAU, Peter; DUCAN, Dudley. The Process of Stratification. In: Blau, P; Ducan, D. The American Occupational Structure. New York: Wiley, 1967, p. 486-497.

BLUMER, Hebert. Social Psychology. In: Emerson Peter Schmidt. Man and Society: A Substantive Introduction to the Social Science. New York: Prentice-Hall, 1937, p. 144-198.

The Methodological Position of Symbolic Interactionism. In: BLUMER, H. Symbolic Interactionism: Perspective and Method. Berkeley: University of California Press, 1986, p. 1-60. 
BRASIL. Estatuto da Criança e do Adolescente. Disponível em: <http://www.planalto. gov.br/ccivil_03/LEIS/L8069.htm>. Acesso em: fev. 2009.

BRYANT, Brenda; ZVONKOVIC, Anisa; REYNOLDS, Paula. Parenting in relation to child and adolescent vocational development. Journal of Vocational Behavior. n. 69, mar. 2006. pp. 149-175.

COOLEY, Charles. Human Nature and the Social Order (Revised edition). New York: Charles Scribner's Sons, 1922.

FARR, Robert. As Raízes da Psicologia Social Moderna. Petrópolis: Vozes, 1996.

FEATHERMAN, David; HALLER, Archibald. The Social Psychological Legacy of Otis Dudley Ducan. Science Direct. Elsevier. May 2007.

FOUCAULT, Michel. A verdade e as formas jurídicas. Rio de Janeiro: NAU Ed., 1996.

HONNETH, Axel. Atualização Sistemática: a estrutura das relações sociais de reconhecimento. In: HONNETH, Axel. Luta por Reconhecimento. São Paulo: Editora 34, 2009, p. 117-154.

KHATTAB, Nabil. Explanining Educational aspirations of Minority Students: the role of social capital and students' perceptions. Social Psychology of Education. Kluwer ACADEMIC Publishers. vol. 6, 2003.

LAPAN, Richard; HINKELMAN, Jeanne; ADAMS, Angela; TURNER, Sherri. Understanding Rural Adolescents Interests, Values, and Efficacy Expectations. Journal of Career Development. Human Sciences Press. v. 26, winter, 1999.

MEAD, George. Mind, Self, and Society: from the standpoint of a social behaviorist. Chicago and London: The University of Chicago Press, 1934.

SALES, Marta. Aspirações Ocupacionais e Realização do Status. 2014. 219 f. Tese (Doutorado em Sociologia) - Faculdade de Filosofia e Ciência Humanas, Universidade Federal de Minas Gerais, Belo Horizonte.

SALVADORI, Mateus;HONNETH, Axel. Luta por reconhecimento: a gramática moral dos conflitos sociais. São Paulo: Ed. 34, 2003, p. 189-192.

SEWELL, William; HALLER, Archibald; OHLENDORF, W. George. The Educational and Early Occupational Status Attaiment Process: replication and revision. American Sociological Review, v. 35, dez., 1970.

Recebido em 09/12/2015

Aprovado em 13/11/ 2016

\section{Como citar este artigo:}

SALES, Marta Santos; FERNANDES, Danielle Cireno. Aspirações e Status Ocupacional: Qual a distância entre o sonho e a realização? Contemporânea - Revista de Sociologia da UFSCar, v. 7, n. 1, jan.- jun. 2017, pp. 193-210. 